\title{
An aligned fibrous and thermosensitive hyaluronic acid-puramatrix interpenetrating polymer network hydrogel with mechanical properties adjusted for neural tissue
}

\author{
Negar Abbasi Aval ${ }^{1,2,3}$, Rahmatollah Emadi ${ }^{2}$, Ali Valiani ${ }^{3}$, Mahshid Kharaziha $^{2}$, and \\ Anna Finne-Wistrand ${ }^{1, *}$ (i) \\ ${ }^{1}$ Department of Fibre and Polymer Technology, School of Engineering Sciences in Chemistry, Biotechnology and Health, KTH Royal \\ Institute of Technology, Teknikringen, 56-58, 10044 Stockholm, SE, Sweden \\ ${ }^{2}$ Biomaterials Research Group, Department of Materials Engineering, Isfahan University of Technology, Isfahan 84156-83111, Iran \\ ${ }^{3}$ Department of Anatomical Science, School of Medicine, Isfahan University of Medical Sciences, Isfahan, Iran
}

Received: 11 August 2021

Accepted: 13 November 2021

Published online:

3 January 2022

(C) The Author(s) 2021

\begin{abstract}
Central nervous system (CNS) injuries such as stroke or trauma can lead to longlasting disability, and there is no currently accepted treatment to regenerate functional CNS tissue after injury. Hydrogels can mimic the neural extracellular matrix by providing a suitable 3D structure and mechanical properties and have shown great promise in CNS tissue regeneration. Here we present successful synthesis of a thermosensitive hyaluronic acid-RADA 16 (Puramatrix ${ }^{\mathrm{TM}}$ ) peptide interpenetrating network (IPN) that can be applied in situ by injection.

Thermosensitive hyaluronic acid (HA) was first synthesized by combining HA with poly( $N$-isopropylacrylamide). Then, the Puramatrix ${ }^{\mathrm{TM}}$ self-assembled peptide was combined with the thermosensitive HA to produce a series of injectable thermoresponsive IPNs. The HA-Puramatrix ${ }^{\mathrm{TM}}$ IPNs formed hydrogels successfully at physiological temperature. Characterization by SEM, rheological measurements, enzymatic degradation and swelling tests was performed to select the IPN optimized for neurologic use. SEM images of the optimized dry IPNs demonstrated an aligned porous structure, and the rheological measurements showed that the hydrogels were elastic, with an elastic modulus of approximately $500 \mathrm{~Pa}$, similar to that of brain tissue. An evaluation of the cellmaterial interactions also showed that the IPN had biological characteristics required for tissue engineering, strongly suggesting that the IPN hydrogel possessed properties beneficial for regeneration of brain tissue.
\end{abstract}

Handling Editor: Dale Huber.

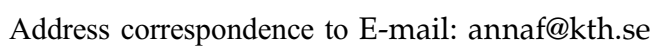




\section{Introduction}

Stroke is a degenerative injury of the central nervous system (CNS) and is one of the major causes of longterm disabilities in humans as well as the third largest cause of death in the world [1]. By grafting neural stem cells to the CNS it may be possible to treat stroke. Neural stem cells can be used for regeneration because they have the capability to release neurotrophic factors and differentiate into all kinds of neural cells [2,3]. Using stem cells often requires a three-dimensional scaffold for attachment and to provide an appropriate environment for cell survival and differentiation.

Hydrogel scaffolds have been shown to be a good physiological model of the extracellular matrix, and they are good candidates for encapsulating neural cells since they can be modified to have structural, mechanical and degradation properties similar to biological tissues. Additionally, exogenous cells and axons are able to move into hydrogels due to the size of their micropores [4-6]. Hydrogels that consist of only one polymer are normally not able to provide the mechanical and biological characteristics required for tissue engineering purposes. There are different ways to resolve this problem, for example, by designing composite hydrogels of two polymers, adding nanomaterials such as inorganic, organic, metallic, magnetic and carbonic nanomaterials or making hybrid hydrogels such as interpenetrating polymer networks (IPNs) or semi-interpenetrating polymer networks (semi-IPNs) [7, 8]. Recently, researchers were able to resolve brain tissue engineering-related difficulties by designing and synthesizing IPNs using different polymers with tunable physical, biochemical and mechanical properties based on the requirements of the regeneration progress [9].

The ECM of CNS tissue consists of a broad range of fibrous proteins, such as collagen, fibronectin, laminin, vitronectin and hyaluronic acid (HA). The amount of HA in the extracellular matrix is high, and it has a key role in the growth and migration of fetal cells and mature tissue regeneration. The majority of the ECM in brain is HA; after birth, the ECM in the brain is composed of $25 \%$ HA. Assessing HA hydrogels in vitro has been shown to help cell migration, as a hydrogel can be adjusted to have a loose matrix with a high water absorption capability [10]. It has also been shown that HA has the potential to be an appropriate matrix for neural stem cell encapsulation [11].

HA is a nonsulfated glycosaminoglycan containing D-glucuronic acid and D-N-acetyl glucose amine. HA has positive characteristics such as degradability, chemical and mechanical sustainability, low immune response and high potential for angiogenesis [9]. The molar mass of $\mathrm{HA}$ in brain tissue is high and hinders inflammation, vascularization and neuronal differentiation. When a stroke occurs in the brain, enzymatic degradation of the high molar mass HA begins, generating a low molar mass HA that in turn induces the proliferation of stem cells. Furthermore, low molar mass HA is also effective in the differentiation and migration of neural stem cells. HA with a low molar mass then activates the immune response in the body, leading to endothelial cell proliferation, tubulization and angiogenesis [7]. In addition, HA fibers in natural ECM have the ability to guide the migration of neural cells in the brain by providing physical cues which lead to stem cell proliferation and differentiation [11]. Thermoresponsive hydrogels that form hydrogels after injected in the body are compelling in tissue engineering for different reasons, for example because of the minimally invasive injection procedure. Poly $(N$-isopropylacrylamide) (pNIPAAm) is a thermosensitive polymer which has the ability to form a gel at $32{ }^{\circ} \mathrm{C}$. Adding pNIPAAm to polymers and hydrogels designed for tissue engineering purpose, leads to thermoresponsive scaffolds with more complex and appealing properties [12].

Another important substance for successful brain tissue engineering is Puramatrix ${ }^{\mathrm{TM}}$ (RADA), a 16-amino-acid synthetic peptide that is resuspended in water. This is a self-assembling nanofibrous hydrogel scaffold that is assembled through the ionic self-complementarity of $\beta$ sheet oligopeptides under physiological conditions $\left(T=37^{\circ} \mathrm{C}\right.$ and $\left.\mathrm{pH}=7\right)$. A range of concentrations is known to have excellent effects on reknitting the lesion site in the spinal cord and brain after injury. RADA has been applied in a variety of neural tissue engineering applications and demonstrates a positive effect on neuronal growth, 
differentiation and synapse formation. One of the distinguishing properties of RADA is the ability to provide a fibrous 3D matrix with a fiber size similar to ECM and the ability to fill the injury site with a self-assembling, potent hydrogel [13-16].

Our starting hypothesis was that the mechanical properties of an injectable IPN hydrogel based on HA and RADA can be adjusted for the mechanical properties required of neural tissue. We also hypothesized that an aligned porous structure would lead to the growth and alignment of endogenous and exogenous neural stem cells. Such IPNs would be of use for brain tissue regeneration. We therefore developed IPN hydrogels based on high molar mass HA and RADA, combining the HA hydrogel and RADA peptide, tuning the thermosensitivity, mechanical properties and fibrous structure. Thermosensitive HA was first synthesized by attaching $N$-isopropylacrylamide (NIPAAm) to $\mathrm{HA}$, which in turn was combined with RADA in different ratios. The IPN was formed by increasing the temperature, and these thermosensitive injectable IPNs were carefully characterized and evaluated for brain tissue engineering. The morphological, chemical and mechanical properties of the hydrogels were assessed, and the cell-material interactions were evaluated by following the viability and morphology of cells encapsulated in the hydrogels.

\section{Materials and methods}

\section{Materials}

Hyaluronic acid sodium (molecular weight, $\left.\sim 1.6 \times 10^{6}\right)$, adipic dihydrazide $(\mathrm{ADH})$, 1-ethyl-3-(3-dimethylaminopropyl) carbodiimide hydrochloride (EDC), 1-hydroxybenzotriazole hydrate (HOBt), 4,4'-azobis (4-cyanovaleric acid) (ACA), sodium chloride $(\mathrm{NaCl})$, dimethyl sulfoxide (DMSO), hyaluronidase (lyophilized powder, 400-1000 units/mg solid) and ethanol were purchased from Sigma-Aldrich and were used as received. NIPAAm was purchased from SigmaAldrich and purified by recrystallization in $n$-hexane/toluene (40/60) before use. The Corning®Puramatrix $^{\mathrm{TM}}$ peptide hydrogel with $1 \% \mathrm{w} \mathrm{v}^{-1}$ RADA- 16 was provided by Corning. The $\mathrm{H}_{2} \mathrm{O}$ used for this work was Milli-Q water.

\section{Synthesis}

Synthesis of aminated hyaluronic acid (AHA)

$\mathrm{HA}$ was dissolved in $\mathrm{H}_{2} \mathrm{O}$ at a concentration of $3 \mathrm{mg} \mathrm{mL}^{-1}$. ADH was added to this solution in a 30-fold molar excess. The $\mathrm{pH}$ of the reaction mixture was adjusted to 6.8 with $0.1 \mathrm{M} \mathrm{NaOH} / 0.1 \mathrm{M} \mathrm{HCl}$. EDC ( $1 \mathrm{mmol})$ and HOBt $(1 \mathrm{mmol})$ were dissolved in DMSO/H2O (1:1, $1 \mathrm{~mL}$ each). After mixing, the $\mathrm{pH}$ of the reaction was maintained at 6.8 by the addition of $0.1 \mathrm{M} \mathrm{NaOH}$, and the reaction was continued overnight (a scheme of the reaction is presented in Scheme 1a). The following day the $\mathrm{pH}$ was adjusted to 7.0 with $0.1 \mathrm{M} \mathrm{NaOH}$, and the functionalized HA was exhaustively dialyzed (MW cutoff 12-14,000) against $\mathrm{H}_{2} \mathrm{O}$. $\mathrm{NaCl}$ was added to produce a $5 \% \mathrm{w} \mathrm{v}^{-1}$ solution, and the modified HA was precipitated by addition of 3 volume equivalents of ethanol. The precipitate was redissolved in $\mathrm{H}_{2} \mathrm{O}$ at a concentration of approximately $5 \mathrm{mg} \mathrm{mL}^{-1}$, purified with dialysis tubes (MW cutoff 12-14,000) and freeze-dried [17].

\section{Synthesis of polyNIPAAm-COOH}

Five grams of NIPAAm and $60 \mathrm{mg}$ of ACA were dissolved in $25 \mathrm{ml}$ of methanol with a concentration of $20 \mathrm{wt} \%$ monomer solution, $\mathrm{N}_{2}$ was added for $10 \mathrm{~min}$, and the solution was incubated at $68^{\circ} \mathrm{C}$ for $3 \mathrm{~h}$ (Scheme $1 \mathrm{~b}$ ). The polymer was precipitated by slowly adding the solution into water at $60^{\circ} \mathrm{C}$, and the polymer was washed twice with water $\left(60^{\circ} \mathrm{C}\right)$. The polymer was then dissolved in water and freezedried at $-50{ }^{\circ} \mathrm{C}[12]$.

\section{Synthesis of thermosensitive HA-PNIPAAm}

For the synthesis of the HA-PNIPAAm copolymer, two different amounts of PNIPAAm were considered. The first one, which was named HA-1, was synthesized using AHA/poly(NIPAAm-COOH)/ EDC with ratios of $0.5 / 0.5 / 0.1$, and the second one was named HA-2 using 0.5/1/0.2. To activate the $\mathrm{COOH}$ groups of poly(NIPAAM-COOH), the polymer was incubated with EDC at $4{ }^{\circ} \mathrm{C}$ for $48 \mathrm{~h}$. Then, AHA was added to the poly(NIPAAM-COOH)/EDC solution and allowed to react for $24 \mathrm{~h}$. The final mixture was dialyzed exhaustively against hot water $\left(65{ }^{\circ} \mathrm{C}\right)$ for 3 days to purify the product. The final product was freeze-dried at $-50{ }^{\circ} \mathrm{C}$ [12]. 
(a)

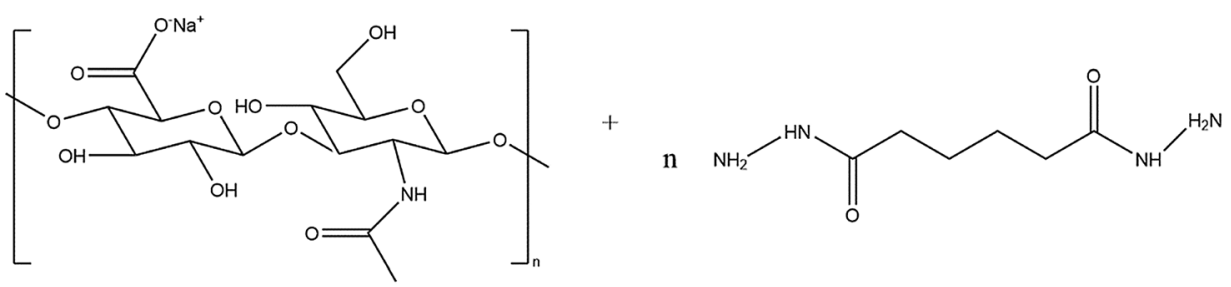
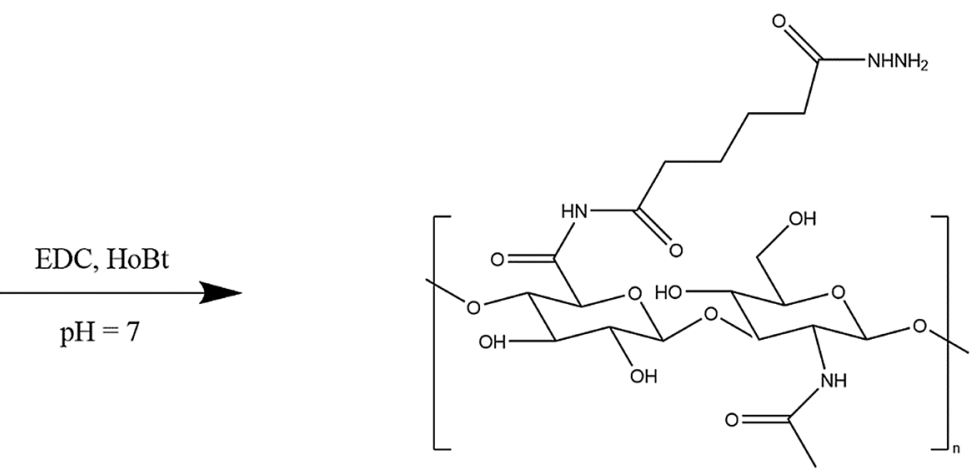

(b)

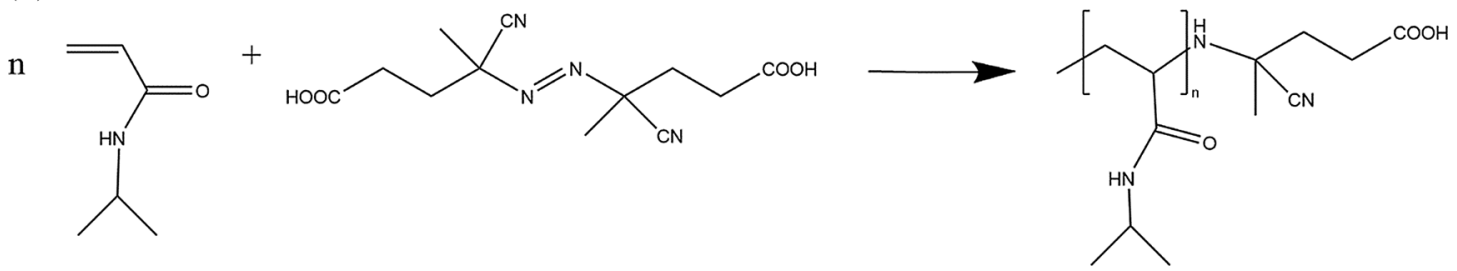

Scheme 1 a Synthesis of aminated hyaluronic acid (AHA), $\mathbf{b}$ synthesis of poly(NIPAAm-COOH).

\section{Fabrication of HA-RADA IPNS}

For the synthesis of HA-RADA IPNs, 3 different concentrations, 1,5 and $10 \mathrm{mg} / \mathrm{ml}$, of Puramatrix ${ }^{\mathrm{TM}}$ were used. HA-1 and HA-2 were mixed physically at room temperature with 3 ratios of RADAs to produce 6 different IPNs: HA-1-RADA-1, HA-1-RADA-5, HA1-RADA-10, HA-2-RADA-1, HA-2-RADA-5 and HA2-RADA-10.

\section{Characterization}

\section{Characterization of HA and HA-RADA IPN hydrogels}

The structure of HA hydrogels was determined by ${ }^{1} \mathrm{H}$ NMR in $0.1 \mathrm{M}$ sodium phosphate buffer solution $(\mathrm{pH}=7)$ at room temperature by a Bruker Avance at $300 \mathrm{MHz}$. The buffers were prepared with the following method: First, the desired amount of $\mathrm{Na}_{2}$ $\mathrm{HPO}_{4}$ was added, and the $\mathrm{pH}$ was measured, and second, $\mathrm{NaH}_{2} \mathrm{PO}_{4}$ was added gradually to reach a favorable $\mathrm{pH}$. The chemical composition of the HA hydrogels was verified through attenuated total reflectance-Fourier transform infrared spectroscopy (ATR-FTIR, PerkinElmer Spectrum 2000). The morphology of the HA and HA-RADA hydrogels was characterized by tabletop scanning electron microscopy (SEM, Hitachi TM1000).

\section{Rheology}

The gelling behavior of HA and HA-RADA hydrogels was determined by a rheometer (DHR2, TA instruments) with parallel plates of $25 \mathrm{~mm}$ in diameter. Hydrogels in sol mode were applied on the plates, and a temperature ramp between 25 and $37^{\circ} \mathrm{C}$ was recorded. Storage modulus $\left(\mathrm{G}^{\prime}\right)$ and loss modulus $\left(\mathrm{G}^{\prime \prime}\right)$ of HA and HA-RADA hydrogels were evaluated during heating the gels. A frequency sweep of the samples was also recorded at $37^{\circ} \mathrm{C}$ to measure the $G^{\prime}$ and $G^{\prime \prime}$ using a frequency of $10 \mathrm{~Hz}$. The complex viscosity of HA and HA-RADA 
hydrogels was evaluated as a function of temperature.

\section{Transmission electron microscopy (TEM)}

The structure of RADA was characterized using transmission electron microscopy (TEM, Hitachi HT770D) with 02/05 software. Peptide solutions (as received, without any dilution) were incubated at $4{ }^{\circ} \mathrm{C}$ overnight for self-assembly. A droplet of $10 \mu \mathrm{l}$ of the peptide solution was added to the Au grid, the droplet was deposited on the grid for $30 \mathrm{~min}$ and then removed with paper, and the grid was dried overnight at room temperature.

\section{In vitro enzymatic degradation}

Mass loss of HA and HA-RADA hydrogels in hyaluronidase solution was used to evaluate the enzymatic degradation. Hyaluronidase was dissolved in PBS at a concentration of $100 \mathrm{U} / \mathrm{ml}$. The samples with $5 \mathrm{wt} \%$ were dissolved in PBS and placed in a water bath at $37^{\circ} \mathrm{C}$. After the completion of gelation, they were freeze-dried at $-50{ }^{\circ} \mathrm{C}$ and weighed. The shape of the dried hydrogel was cylindrical, $1 \mathrm{~cm}$ diameter and $5 \mathrm{~mm}$ thickness; three replicates were used for each time point. The dry hydrogels were placed in $1 \mathrm{ml}$ enzyme solution in 24 cell culture well plate and in the oven at $37^{\circ} \mathrm{C}$. The enzyme solution was refreshed daily. At specified time points (1, 3, 7, 14, 28 days), the hydrogels were removed from the enzyme solution, lyophilized at $-50{ }^{\circ} \mathrm{C}$ and weighed. The mass loss was calculated as $100 \% \times\left(\mathrm{W}_{0}-\mathrm{W}_{t}\right) / \mathrm{W}_{0}$, where $\mathrm{W}_{0}$ and $\mathrm{W}_{t}$ represent the initial dry hydrogel weight and degraded hydrogel weight at the specified time points, respectively.

\section{Equilibrium swelling}

The equilibrium swelling ratio of HA and HA-RADA hydrogels was investigated by immersing the hydrogels in both PBS and DMEM solutions at $37^{\circ} \mathrm{C}$. The HA samples were made by dissolving $5 \mathrm{wt} \%$ hydrogels in PBS and placing at $37^{\circ} \mathrm{C}$ for complete gelation. The HA-RADA samples were also made by dissolving $5 \mathrm{wt} \% \mathrm{HA}$ and the specified amount of RADA in PBS at $37^{\circ} \mathrm{C}$. The samples were placed in PBS and DMEM at $37^{\circ} \mathrm{C}$ for $4 \mathrm{~h}$ and then removed, wiped off and weighed. Afterward, the samples were frozen and lyophilized at $-50{ }^{\circ} \mathrm{C}$. The equilibrium swelling ratio (ESR) was calculated by $\left(\mathrm{W}_{s}-\mathrm{W}_{d}\right) / \mathrm{W}_{d}$, where $W_{s}$ and $W_{d}$ represent the initial hydrogel and dry hydrogel weight, respectively. Three repetitions were performed per sample.

\section{Cell viability study}

Dry HA and RADA peptides were sterilized under UV irradiation in a laminar flow hood for $30 \mathrm{~min}$ and then dissolved in DMEM/F12/10\% FBS medium at room temperature to obtain a $5 \mathrm{wt} \%$ solution. The cell density used (human neuroblastoma cell line $\mathrm{SH}$ SY5Y (ATCC)) was $3 \times 10^{6} / \mathrm{mL}$ of IPN solution. After sufficient mixing, the cell-containing solutions were injected into 48-well culture plates and incubated at $37^{\circ} \mathrm{C}$ to form hydrogels. After $10 \mathrm{~min}$, prewarmed DMEM/F12/10\% FBS medium $\left(37^{\circ} \mathrm{C}\right)$ was added to each well and changed daily for 7 days. To evaluate the viability of cells seeded on hybrid hydrogels, a calcein-AM/ethidium homodimer (EthD-III) live/dead assay (Biotium, UK) was performed. After rinsing the cell-cultured samples, 100 $\mu \mathrm{L}$ of live/dead solution consisting of $2 \mu \mathrm{M}$ calcein $\mathrm{AM}$ and $4 \mu \mathrm{M}$ ethidium homodimer was added to the samples to cover the cell monolayer and incubated for $1 \mathrm{~h}$ at $37^{\circ} \mathrm{C}$. The samples were then imaged using an inverted fluorescence microscope.

\section{Results}

\section{Synthesis and characterization of HA hydrogels}

To achieve a successful and functional scaffold for tissue engineering, physical properties such as morphology, porosity, swelling ratio, degradation rate and mechanical properties such as rheological behavior and cellular behavior should match the requirements for regenerating tissue in the intended application. We tuned the physical and mechanical properties of the IPN hydrogels by using two polymers and varying the amount of each polymer.

Aminated HA (AHA) and poly(NIPAAm-COOH) were first synthesized according to Scheme 1. AHA and poly(NIPAAm-COOH) were subsequently used to synthesize two HA-based hydrogels. The first HA hydrogel was named HA-1 and contained a ratio of 0.5/0.5/0.1 of AHA/poly(NIPAAm-COOH)/EDC, 
and the second hydrogel, HA-2, contained a ratio of 0.5/1/0.2 of AHA/poly(NIPAAm-COOH)/EDC.

The synthesis steps were characterized using ATRFTIR (Fig. 1) and ${ }^{1} \mathrm{H}-\mathrm{NMR}$ (Fig. 2).

Chemical structures of HA, NIPAAm, polyNIPAAm and PolyNIPAAm-COOH-AHA hydrogel are presented in ATR-FTIR spectra, Fig. 1. Characteristic peaks of HA (Fig. 1a) are shown at 1615 and $1410 \mathrm{~cm}^{-1}$ for the asymmetric $\mathrm{COO}^{-}$stretching vibration and the symmetric $\mathrm{COO}$ stretching vibration, respectively. NIPAAm (Fig. 1b) demonstrated characteristic peaks at 1617 and $1410 \mathrm{~cm}^{-1}$ which are attributed to $\mathrm{C}=\mathrm{C}$ and $\mathrm{CH}_{2}=$, respectively. Figure 1c shows the spectrum of polyNIPAAm with $\mathrm{COOH}$ functional groups where the peaks at 1714, 1649 and $1539 \mathrm{~cm}^{-1}$ are assigned to terminal carboxylic group, amide I and amide II, respectively. In addition, the peaks at 1388 and $1363 \mathrm{~cm}^{-1}$ are attributed to the bending vibration of isopropyl groups in polyNIPAAm-COOH. The spectrum of AHA-polyNIPAAm (HYA) represented in Fig. 1d shows the characteristic peaks of HA and polyNIPAAm besides a peak at $1750 \mathrm{~cm}^{-1}$ which is assigned to ester group $(-\mathrm{COOR})$ as a sign of polysaccharide $[18,19]$.

Figure 2a displays the spectrum for AHA, where the characteristic peaks of HA are visible at 2.01, 3-4 and 4-6 ppm, which refer to acetyl $\left(-\mathrm{NHCOCH}_{3}\right)$, glucosidic $\mathrm{H}(\mathrm{H} 10)$ and anomeric $\mathrm{H}(2 \mathrm{H})$, respectively $[20,21]$. Characteristic peaks for AHA are represented in the spectrum at 2.2 and $2.4 \mathrm{ppm}$ assigned to the methylene protons of ADH [12]. The characteristic peak at $2.8 \mathrm{ppm}$ visible in Fig. $2 \mathrm{a}$ but much stronger in HA-1 and HA-2 (Fig. 2c, d, respectively) could be in result of adding $\mathrm{ADH}$ to $\mathrm{HA}$ [22].

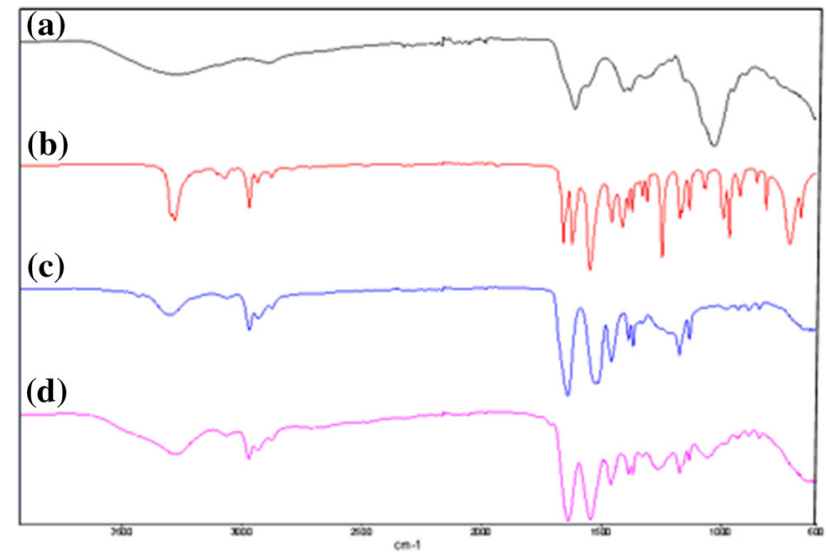

Figure 1 FTIR spectra of a HA, b NIPAAm, c polyNIPAAm$\mathrm{COOH}$ and $\mathbf{d}$ polyNIPAAm-COOH-AHA.

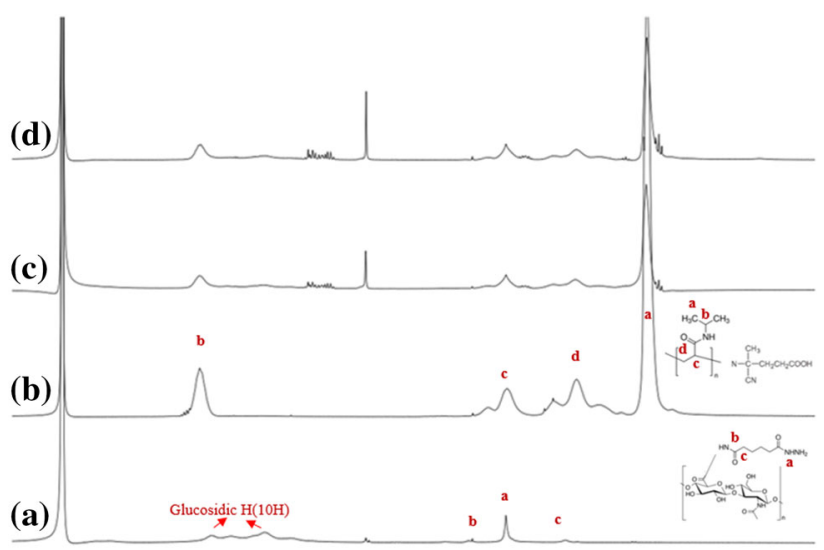

Figure 2 H-NMR spectra of a AHA, b poly(NIPAAm-COOH), c HA-1 and d HA-2.

Figure $1 \mathrm{~b}$ demonstrates the spectrum for poly(NIPAAm-COOH) with peaks at 1.03, 1.47, 1.9 and $3.79 \mathrm{ppm}$, which are attributed to protons of the $\mathrm{CH}_{3},-\mathrm{CH}_{2},-\mathrm{CH}-$ and $-\mathrm{CH}-$ on the isopropyl group, respectively [18]. Figure 1c, d shows the copolymer where the characteristic peaks of AHA and poly(NIPAAm-COOH) are visible in the spectra. In addition, the peaks at 1.1 and $3.9 \mathrm{ppm}$ are assigned to the $-\mathrm{CH}_{3}$ and $-\mathrm{NH}$ groups, respectively [12].

\section{Synthesis of HA-RADA IPN hydrogel}

As discussed, one of the advantages of RADA is its ability to form a fibrous 3D matrix with a fiber size similar to ECM and the idea is to inject the gel in wet state and that the RADA peptide naturally forms the fibrillar structure. However, in order to have a closer look at the fibrous structure of RADA it was herein assessed by TEM and is shown in Fig. 3a using different magnifications. There is a long and wellordered fibrillary structure of the peptide (shown by arrows), and this nanofibrillary structure formation is due to the ability of this peptide to form $\beta$-sheets that are stable over a wide range of $\mathrm{pH}$ values and temperatures.

RADA was blended with the two HA hydrogels in ratios summarized in Table 1.

The morphology of HA-1 and HA-1-RADA hydrogels is demonstrated in the SEM images, Fig. 3b-e, while HA-2 and HA-2-RADA hydrogels are shown in supplementary material, Fig. 1. The SEM images present a porous structure of HA-1, which was then added to different concentrations of 
Figure 3 a TEM image of RADA at two magnifications. SEM images of $\mathbf{b}-\mathbf{e}$ HA-1, HA-1-RADA-1, HA-1RADA-5 and HA-1-RADA10.

Table 1 Composition of the IPN hydrogels
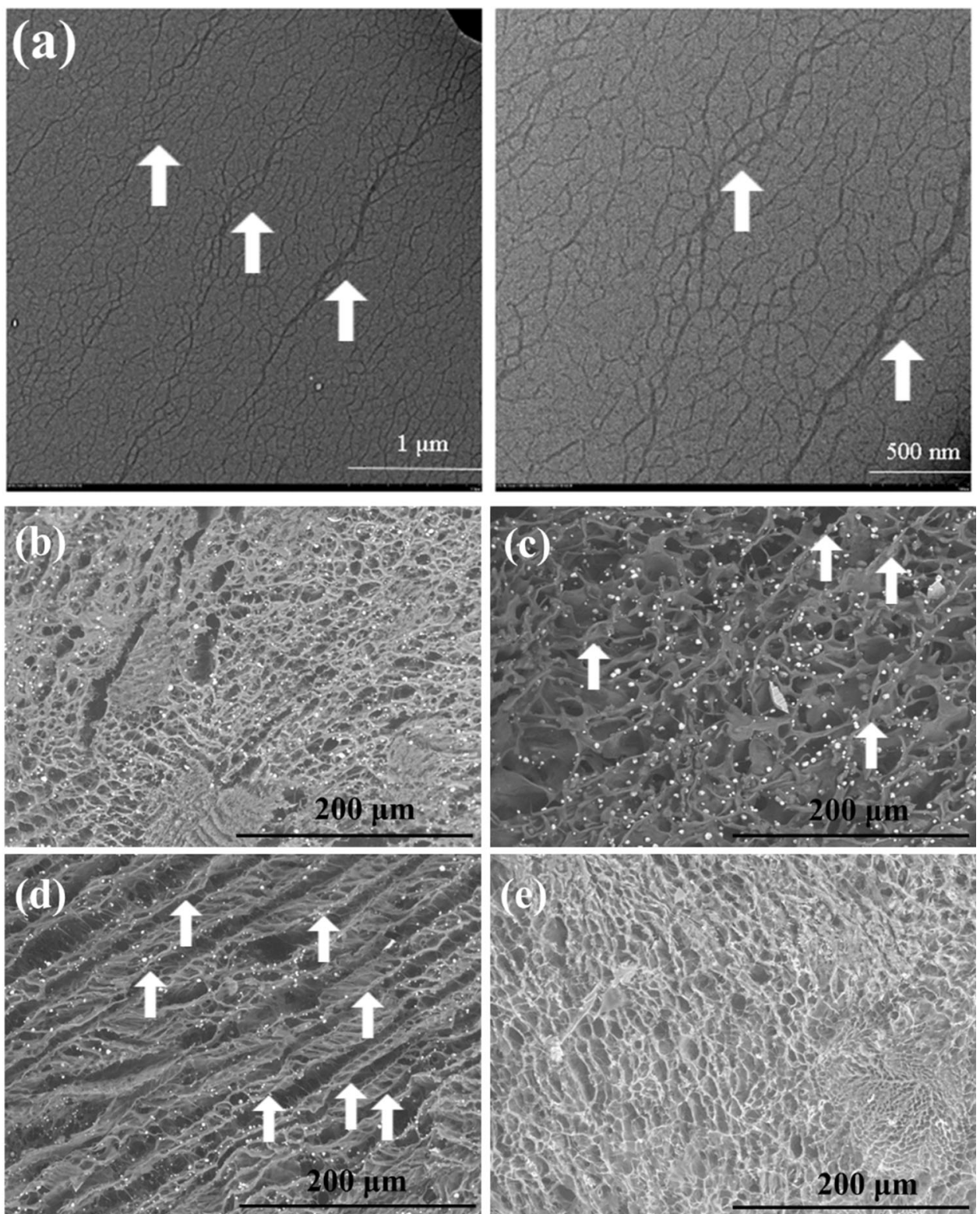

\begin{tabular}{lllll}
\hline & \multicolumn{2}{l}{ AHA:polyNIPAAm-COOH:EDC $(\mathrm{g})$} & ${\text { RADA }\left[\mathrm{mg} \cdot \mathrm{ml}^{-1}\right]}$ \\
\hline HA-1-RADA-1 & 0.5 & 0.5 & 0.1 & 1 \\
HA-1-RADA-5 & 0.5 & 0.5 & 0.1 & 5 \\
HA-1-RADA-10 & 0.5 & 0.5 & 0.1 & 10 \\
HA-2-RADA-1 & 0.5 & 1 & 0.2 & 1 \\
HA-2-RADA-5 & 0.5 & 1 & 0.2 & 5 \\
HA-2-RADA-10 & 0.5 & 1 & 0.2 & 10 \\
\hline
\end{tabular}

RADA to form the IPNs. The SEM image of HA-1RADA-1 illustrates an aligned unidirectional fibrous structure, a structure that is seen more clearly in HA1-RADA-5 (shown by arrows in Fig. 3). However, there was no visible aligned structure in HA-1RADA-10. When we prepared RADA-1 in HA-1RADA-1, we diluted the Puramatrix ${ }^{\mathrm{TM}} 10$ times leading to water surrounding the peptide which froze 
and formed ice in the direction of the peptide fibers. Then the fibers dried during the freeze-drying process and generated the aligned porous structure of RADA. When increasing the concentration of RADA to $5 \mathrm{mg} / \mathrm{ml}$ fabricating HA-1-RADA-5 hydrogel, a more aligned structure was observed. This phenomenon could be explained by a higher concentration that leads to alignment of ice with the peptide. When increasing the concentration of RADA to $10 \mathrm{mg} / \mathrm{ml}$ in HA-1-RADA-10, however, no aligned or arranged morphology was observed. We believe that the high viscosity at this concentration did not allow ice formation along the peptide fibers; therefore, the final structure of the hydrogel was mostly affected by the morphology of the HA, which is porous and without aligned formation. SEM illustration of HA-2 and HA-RADA hydrogels is shown in Supplementary Fig. 1.

Our findings regarding aligned porous hydrogels are in agreement with other research that has been done via a two-step method, directional freezing and directional freeze-drying of water-soluble or organicsoluble polymers. It has been shown that the synthesis of aligned poly(vinyl alcohol) can be performed via a two-step method in which the temperature of the aqueous polymer solution is first slowly lowered to the liquid nitrogen temperature, which resulted in controlled ice crystal growth and orientation. In the second step, freeze-drying was used to remove the ice crystals that functioned as templates to achieve a porous cylindrical monolith. This aligned pore structure was explained by the phase separation that occurred during directional freezing. The pore size was controlled by adjusting the size of the ice crystals, which could be controlled by changing the concentration of polymer solution [23]. Similar research on the fabrication of aligned porous gelatin structures used different concentrations of gelatin: $1,3,4$ and $5 \%\left(\mathrm{~g} \mathrm{ml}^{-1}\right)$. When increasing the concentration of gelatin, it was not possible to achieve an aligned porous structure. The solution viscosity increased with increasing gelatin concentration, and the solvent (water) did not arrange during the freezing process; therefore, ice crystal formation and arrangement were limited [19].

\section{Rheological analysis}

Rheological behavior provides information on the stiffness and viscoelastic properties of the hydrogel and valuable data for understanding the structure of the IPN and how the hydrogel behaves under physiological conditions. The mechanical properties of the HA-based hydrogels and IPN hydrogels were assessed by monitoring viscoelastic parameters using a temperature ramp and frequency sweep mode of a rheometer. All hydrogels and IPNs demonstrated the mechanical properties of solids, and they showed a constant elastic modulus with $G^{\prime}>G^{\prime \prime}$ for all samples, which is proof of elastic [24].

Figure 4a illustrates the complex viscosity of HA-1 and HA-1-RADA thermoresponsive hydrogels in relation to temperature when the temperature increases from 25 to $40{ }^{\circ} \mathrm{C}$. It is obvious that the viscosity is increasing after $32{ }^{\circ} \mathrm{C}$, which relates to the gelation process. In Fig. $4 \mathrm{~b}, \mathrm{c}, \mathrm{HA}-1$ shows an increasing elastic modulus $\left(\mathrm{G}^{\prime}\right)$ and viscous modulus $\left(G^{\prime \prime}\right)$ while increasing the temperature from 30 to $32{ }^{\circ} \mathrm{C}$ (sol gel transition was monitored by changing the color of the gel from noncolor to white at $30^{\circ} \mathrm{C}$, data not shown here). Since $\mathrm{G}^{\prime}>\mathrm{G}^{\prime \prime}, \mathrm{HA}-1$ and IPNs are defined as elastic hydrogels. When RADA at concentrations of $0.1 \%$ and $0.5 \% \mathrm{w} \mathrm{v}^{-1}$ was added to the HA-1 hydrogel, the elastic and viscous modulus of the IPNs decreased. However, with the addition of $1 \% \mathrm{w} \mathrm{v}^{-1}$ RADA (without any dilution), both the elastic and viscous moduli increased again, reaching the same values as those for HA-1. For frequency sweep mode, the frequency of $10 \mathrm{~Hz}$ was chosen since it was shown by Garcia-rill et al. [25] that the natural frequency of brain tissue is $10 \mathrm{~Hz}$ while walking but could decrease when a person is less active or sleep and could increase during more complex activities. In frequency sweep mode (Fig. 4c, d), the elastic modulus of HA-1 at a frequency of $10 \mathrm{~Hz}$ was $500 \mathrm{~Pa}$, and the elastic modulus of HA-1RADA-10 was $400 \mathrm{~Pa}$, which is close to the elastic modulus of brain tissue ( $500 \mathrm{~Pa}$ ). It has been shown that tissues with elastic modulus of $500 \mathrm{~Pa}$ and softer at frequency of $0.001-10 \mathrm{~Hz}$ have the ability to induce differentiation of cultured stem cell to neural cells. [26].

\section{Swelling properties}

It has been observed that in IPNs with different hydrophilic polymers, the morphology of the hydrogel dictates the swelling behavior. We assessed the swelling properties of hydrogels and IPNs in phosphate-buffered saline (PBS) and cell culture 

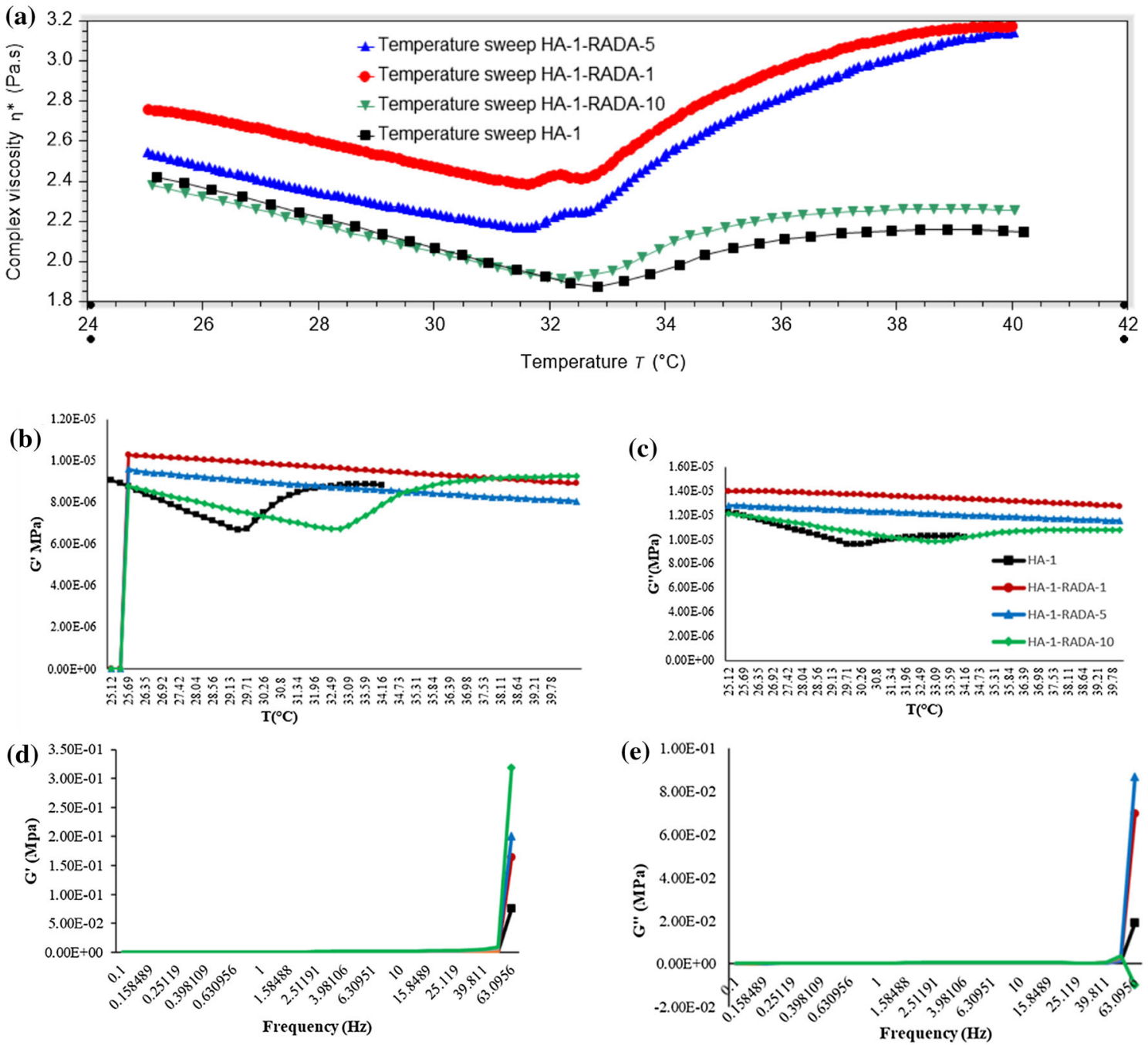

Figure 4 The viscoelastic behavior of HA-1 and IPNs was studied by measuring the $\mathrm{G}^{\prime}$ and $\mathrm{G}^{\prime \prime}$ moduli of the gels. a complex viscosity of gels, $\mathbf{b}, \mathbf{c} \mathrm{G}^{\prime}$ and $\mathrm{G}^{\prime \prime}$ as a function of temperature and $\mathbf{d}, \mathbf{e} \mathrm{G}^{\prime}$ and $\mathrm{G}^{\prime \prime}$ as a function of frequency.
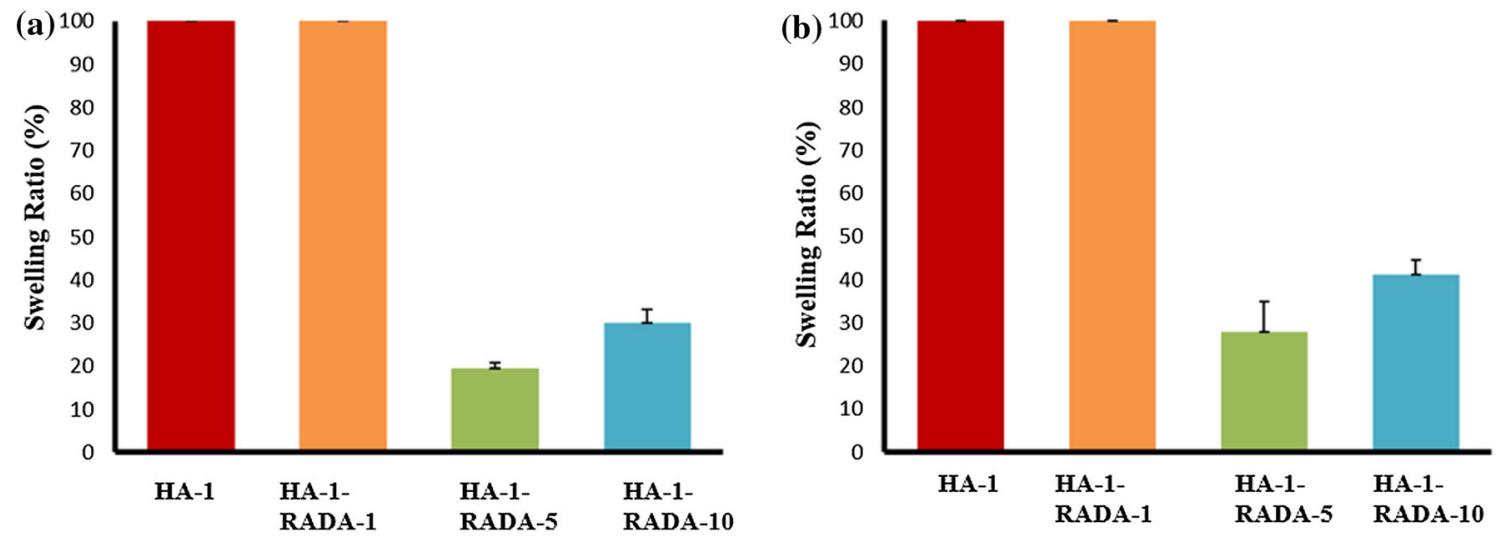

Figure 5 Swelling properties of HA-1 and IPNs in a cell culture medium and b PBS. Red (HA-1), orange (HA-1-RADA-1), green (HA-1RADA-5), blue (HA-1-RADA-10). 
medium. The results are presented in Fig. 5. It was obvious that the swelling and absorption of water in HA-1 and HA-1-RADA-1 hydrogels in both PBS and cell culture medium was approximately $100 \%$. When more RADA was added to the HA-1-RADA-5 sample, the swelling decreased to $27.3 \%$ and $19.5 \%$ in PBS and cell culture medium, respectively. Similar observations were observed for the swelling results of HA-1-RADA-10, with $41.2 \%$ and $30.4 \%$ swelling in PBS and cell culture medium, respectively. Notably, the swelling ratios and water absorption in the cell culture medium were lower than the swelling ratios in PBS. This observation could be due to a lower tendency of hydrogels to undergo water absorption in cell culture medium because of the presence of monosaccharides, amino acids and serum proteins, which could cause less swelling and more shrinkage. The temperature during swelling was $37^{\circ} \mathrm{C}$, which might also improve the adsorption of proteins from serum (present in cell culture medium) onto hydrogel surfaces, improve hydrophobic interactions and reduce swelling and water absorption [27]. It is obvious that with increasing amounts of RADA, swelling decreased. The results also indicate that the most important agent for water absorption in these IPNs was HA, and less HA led to decreased swelling. It has been shown previously that fibrous structures have a lower swelling ratio than porous structures [28] which supports our results. The porous structure of HA-1 and HA-1-RADA-1 had a higher swelling ratio compared to HA-1-RADA-5 and HA-1-RADA 10 , which had fibrous structures. HA-1-RADA-5 with $5 \mathrm{wt} \%$ RADA showed an aligned fibrillar structure, which led to the lowest swelling ratio, while in HA-1RADA-10, a higher concentration of RADA led to a less fibrous and more porous structure, which yielded more water absorption and swelling. It has been shown by others that a swelling level of $40 \%$ in an HA-PEG hydrogel is sufficient for use as an injectable hydrogel for the regeneration of injured spinal cord. This low swelling ensures a stable gel after injection, which is effective in filling the injury site and facilitating the regeneration process [29].

\section{Degradation}

To evaluate the degradation properties of the hydrogels and IPNs, mass loss-time diagrams were used. Mass loss for HA-1 was 30\%, 25\%, 10\% and $30 \%$ at $3,7,14$ and 28 days, respectively (Fig. 6). In

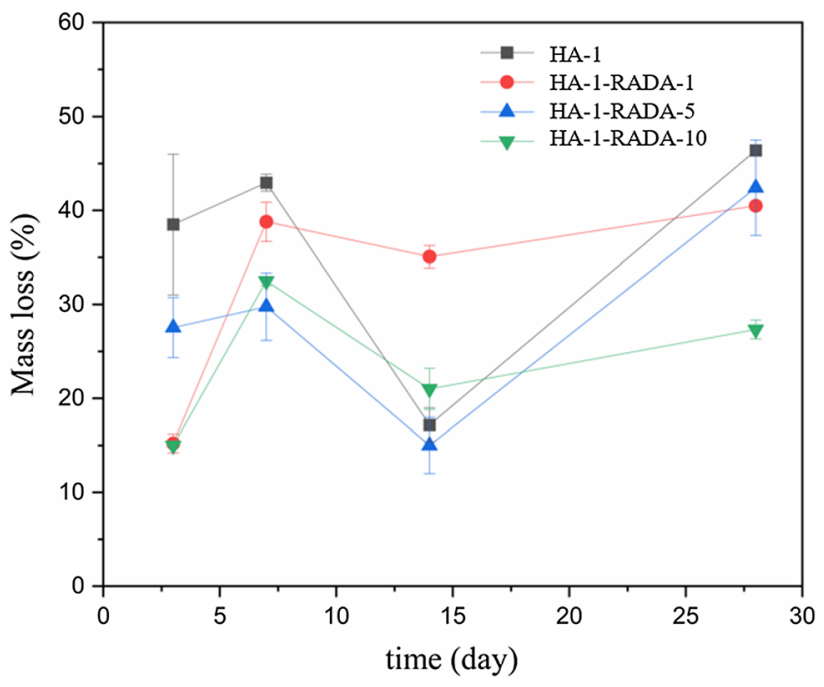

Figure 6 Mass loss-time diagram for HA-1 and IPNs. Blue (HA1-RADA-10), green (HA-1-RADA-5), orange (HA-1-RADA-1), red (HA-1).

HA-1-RADA-1 and HA-1-RADA-5, the mass loss after 28 days was $25 \%$ and $33 \%$, respectively.

The reason for the decreased mass loss for HA-1RADA-1 and HA-1-RADA-5 after 14 days is regelling and recoupling of the degraded products. Nicodemus et al. [29] showed effects of many factors on regelling of degraded alginate hydrogels such as solvents in the body and degraded tissue products which can lead to exchange of dipolar cations to monopolar cations and dissolving of the polymeric chains and hydrogen bondings which could lead to recoupling of the degraded products and finally decreased mass loss. A successful scaffold for CNS regeneration should have a degradation half-life of approximately 1-2 months [30,31]. Here, hydrogel HA-1 had a half-life of almost 1 month, but by adding RADA-16 in different concentrations we believe that the degradation rate decrease gives adequate time for neurogenesis to take place.

\section{Cell-material interactions}

The results of cell survival in HA-1 and the IPNs are illustrated in Fig. 7a-d. The green color (Calcein Am) demonstrates living cells, and the red color (ethidium homodimer) shows dead cells. The cells were uniformly dispersed in HA-1 and their IPNs. The spherical morphology of the cells was preserved for up to 7 days. The same observation has been 
Figure 7 Live-dead assay of a HA-1, b HA-1-RADA-1, c HA-1-RADA-5 and d HA-1RADA-10 at 7 days.
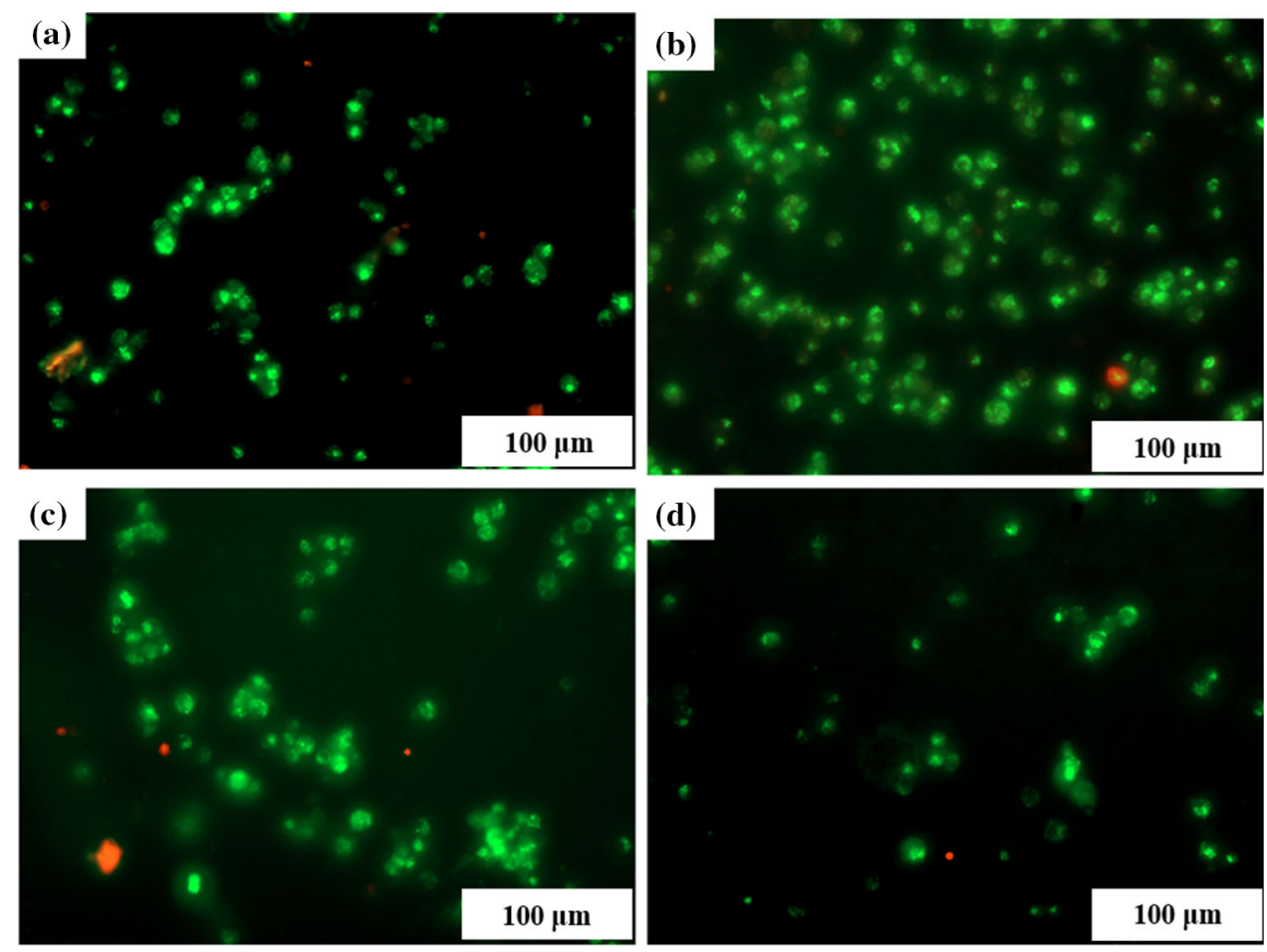

reported by others using HA-silk and gelatin-silk IPN hydrogels, who demonstrated that in IPN hydrogels with two hydrophilic polymers the cultured cells showed spherical morphology for up to 3 days $[32,33]$. The mechanical properties of the IPN hydrogels are important since the cell behavior is determined to a great extent by the surface as well as the mechanical properties of the scaffold. It has for example been shown that expansion of cultured cells in IPN hydrogels of gelatin methacrylate (GelMa) and polycaprolactone (PCL) was lower compared to gelatin hydrogel, which was due to the higher stiffness of the GelMa-PCL IPN [34]. Additionally, it was shown that the higher mechanical properties of the hydrogel hindered endogenous cell entrance into the IPN hydrogel.

\section{Discussion}

As discussed before, HA fibers in natural ECM are able to guide the migration of neural cells in the brain as they provide physical cues for them which lead to stem cell proliferation and differentiation [11]. Also, RADA with 3D fibrous structure formation in which the fiber size is similar to natural ECM could have a positive effect on neuronal growth, differentiation and synapse formation [35]. Thus, the IPN platform has the potential to provide neural stem cell growth and differentiation toward mature neural cells in the lesion site if injected in situ.

To achieve a successful and functional tissue engineering scaffold, physical properties such as morphology, porosity, swelling ratio, degradation rate as well as mechanical properties such as rheological behavior and cellular behavior must match tissue properties in which it would be applied. In IPN hydrogels, a broad range of physical and mechanical properties can be attained by changing the type and quantity of the components. Here we developed an IPN hydrogel based on HA and Puramatrix with different concentration of each in order to optimize the scaffold. The IPN can be formed by increasing the temperature, since both the HA and Puramatrix are temperature sensitive. This kind of IPN is easy to form as the only factor controlling the formation is temperature, so that there is no need for cytotoxic crosslinking agents or UV [36, 37]. Moreover, the temperature-responsive IPN is a very easily applicable and low invasive scaffold where the components can be added to each other and then injected in to the body, where crosslinking and entangling of both components take place at body temperature. Adding Puramatrix to HA-1 has been shown to change the structure of the hydrogel to that of an aligned porous 
structure with less swelling ratio in both PBS and medium, which can be effective in directing the migration and growth of the neural cells. Directing the growth of the neural stem cells, along with their attachment and guidance, is critical in neural tissue regeneration. It has been shown that a composite of electrospun polymeric nanofibers inside collagen hydrogel can have a great effect on spinal cord regeneration as the electrospun fibers provide a suitable surface for cell attachment, growth and migration [38]. The effect of aligned nanofibers composed of PCL, fibrin and carbon nanotubes on growth guidance and differentiation of neural stem cells in neural tissue regeneration has been shown [39]. These composite nanofibers were encapsulated in gelatin methacrylate hydrogel which was crosslinked using UV, after which the composite nanofibers and the crosslinked hydrogel were crosslinked together again with UV. This composite hydrogel with great similarity to the natural 3D neural tissue was efficient in aligned growth and differentiation of neural stem cells. Here, adding Puramatrix to the thermosensitive hydrogel as a nanofibrous structure provided a surface for cell attachment and growth. Also, Puramatrix is a self-assembling peptide with functional groups so there is no necessity for further functionalization of the hydrogel which is advantageous in tissue regeneration and vascularization.

\section{Conclusion}

A thermoresponsive injectable IPN hydrogel based on HA and Puramatrix ${ }^{\mathrm{TM}}$ with mechanical and physical properties similar to brain ECM has been designed. IPN hydrogels were synthesized using two different HA-to-NIPAAm ratios and three different Puramatrix $^{\mathrm{TM}}$ concentrations and named HA-1RADA-1，HA-1-RADA-5，HA-1-RADA-10， HA-2RADA-1, HA-2-RADA-5 and HA-2-RADA-10. We demonstrated the effect of adding Puramatrix ${ }^{\mathrm{TM}}$ to HA on morphology and rheological behavior. Adding Puramatrix ${ }^{\mathrm{TM}}$ to modified HA changed the structure of the hydrogel to an aligned porous structure with a lower swelling ratio in both PBS and cell culture medium in addition to a lower storage modulus, which can be effective in directing the migration and growth of neural cells. Due to its mechanical properties and hydrogel structure as well as its injectability, it is suggested that the synthesized
IPN is a material worthy of further study for the treatment of CNS degenerative injuries such as stroke or trauma.

\section{Acknowledgements}

The authors acknowledge financial support from the Swedish Foundation for Strategic Research (RMA150010). The authors would also like to acknowledge Dr. Ali Valiani, passed away because of cancer, for his efforts in this project.

\section{Author contributions}

NAA helped in conceptualization, methodology, validation, investigation, resources, writing-original draft, writing-review \& editing, visualization. $R E$ and $A V$ were involved in supervision and funding acquisition. $M K$ helped in conceptualization, validation, writing-review \& editing, supervision. AFW contributed to validation, resources, supervision, project administration, writing-review \& editing, funding acquisition.

\section{Funding}

Open access funding provided by Royal Institute of Technology.

\section{Declarations}

Conflict of interest The authors declare that they have no competing interest.

Supplementary Information: The online version contains supplementary material available at http s://doi.org/10.1007/s10853-021-06733-0.

Open Access This article is licensed under a Creative Commons Attribution 4.0 International License, which permits use, sharing, adaptation, distribution and reproduction in any medium or format, as long as you give appropriate credit to the original author(s) and the source, provide a link to the Creative Commons licence, and indicate if changes were made. The images or other third party material in this article are included in the article's Creative Commons licence, unless indicated otherwise in a credit line to 
the material. If material is not included in the article's Creative Commons licence and your intended use is not permitted by statutory regulation or exceeds the permitted use, you will need to obtain permission directly from the copyright holder. To view a copy of this licence, visit http://creativecommons.org/licen ses/by $/ 4.0 /$.

\section{References}

[1] Vishwakarma SK, Bardia A, Tiwari SK, Paspala SA, Khan AA (2014) Current concept in neural regeneration research: NSCs isolation, characterization and transplantation in various neurodegenerative diseases and stroke. J Adv Res A Rev 5:277-294. https://doi.org/10.1016/j.jare.2013.04.005

[2] Cao QI, Zhang YP, Howard RM, Walters WM, Tsoulfas P, Whittemore SR (2001) Pluripotent stem cells engrafted into the normal or lesioned adult rat spinal cord are restricted to a glial lineage. Exp Neuro 167:48-58. https://doi.org/10.1006 /exnr.2000.7536

[3] Lindvall O, Kokaia ZJ (2010) Stem cells in human neurodegenerative disorders - time for clinical translation. J Clin Invest 120:29-40. https://doi.org/10.1172/JCI40543

[4] Hejčl A, Lesný P, Přádný M, Michalek J, Jendelova P, Štulík J, Sykova E (2008) Biocompatible hydrogels in spinal cord injury repair. Physiol Res 57:S121-S132. https://doi.org/10. 1021/cn200030w

[5] Yu Z, Li H, Xia P, Kong W, Chang Y, Fu C, Wang K, Yang Z, Qi Z (2020) Application of fibrin-based hydrogels for nerve protection and regeneration after spinal cord injury. J Biol Eng. https://doi.org/10.1186/s13036-020-00244

[6] Sachs PC, Mollica PA, Bruno RD (2017) Tissue specific microenvironments: a key tool for tissue engineering and regenerative medicine. J Biol Eng. https://doi.org/10.1186/ s13036-017-0077-0

[7] Pan L, Ren Y, Cui F, Xu QJ (2009) Viability and differentiation of neural precursors on hyaluronic acid hydrogel scaffold. J Neurosci Res 87:3207-3220. https://doi.org/10. 1002/jnr.22142

[8] Annabi N, Tamayol A, Uquillas JA, Akbari M, Bertassoni LE, Cha C, Camci-Unal G, Dokmeci MR, Peppas NA, Khademhosseini A (2014) 25th anniversary article: rational design and applications of hydrogels in regenerative medicine. Adv Mater 26:85-124. https://doi.org/10.1002/adma. 201303233

[9] Tunesi M, Batelli S, Rodilossi S, Russo T, Grimaldi A, Forloni G, Ambrosio L, Cigada A, Gloria A, Albani D (2013) Development and analysis of semi-interpenetrating polymer networks for brain injection in neurodegenerative disorders. IJAO 36:762-774. https://doi.org/10.5301/ijao. 5000282

[10] Preston M, Sherman LS (2011) Neural stem cell niches: roles for the hyaluronan-based extracellular matrix. Fronti Biosci. https://doi.org/10.2741/218

[11] Jensen G, Holloway JL, Stabenfeldt SE (2020) Hyaluronic acid biomaterials for central nervous system regenerative medicine. Cells 9:2113. https://doi.org/10.3390/cells9092113

[12] Tan H, Ramirez CM, Miljkovic N, Li H, Rubin JP, Marra K (2009) Thermosensitive injectable hyaluronic acid hydrogel for adipose tissue engineering. Biomaterials 30:6844-6853. https://doi.org/10.1016/j.biomaterials.2009.08.058

[13] Holmes TC, Lacalle SD, Su W, Liu G, Rich A, Zhang S (2000) Extensive neurite outgrowth and active synapse formation on self-assembling peptide scaffolds. PNAS 97:6728-6733. https://doi.org/10.1073/pnas.97.12.6728

[14] Ellis-Behnke RG, Liang YX, You SW, Tay DK, Zhang S, So KF, Schneider G (2006) Nano neuro knitting: peptide nanofiber scaffold for brain repair and axon regeneration with functional return of vision. PNAS 103:5054-5059. h ttps://doi.org/10.1073/pnas.0600559103

[15] McGrath AM, Novikova LN, Novikov LN, Wiberg M (2010) $\mathrm{BD}^{\mathrm{TM}}$ PuraMatrix ${ }^{\mathrm{TM}}$ peptide hydrogel seeded with Schwann cells for peripheral nerve regeneration. Brain Res Bull 83:207-213. https://doi.org/10.1016/j.brainresbull.201 0.07 .001

[16] Guo J, Su H, Zeng Y, Liang YX, Wong MW, Ellis-Behnke RG, So KF, Wu W (2007) Biology, medicine, reknitting the injured spinal cord by self-assembling peptide nanofiber scaffold. NBM 3:311-321. https://doi.org/10.1016/j.nano.2 007.09.003

[17] Bulpitt P, Aeschlimann D (1999) New strategy for chemical modification of hyaluronic acid: preparation of functionalized derivatives and their use in the formation of novel biocompatible hydrogels. J Biomed Mater Res 47:152-169. https://doi.org/10.1002/(SICI)1097-4636(199911)47:2\%3c1 52::AID-JBM5\%3e3.0.CO;2-I

[18] Coronado R, Pekerar S, Lorenzo AT, Sabino MA (2011) Characterization of thermo-sensitive hydrogels based on poly ( $N$-isopropylacrylamide)/hyaluronic acid. Polym Bull 67:101-124. https://doi.org/10.1007/s00289-010-0407-6

[19] Wu Y, Yao J, Zhou J, Dahmani FZ (2013) Enhanced and sustained topical ocular delivery of cyclosporine A in thermosensitive hyaluronic acid-based in situ forming microgels. Int J Nanomed 8:3587

[20] Calce E, Ringhieri P, Mercurio FA, Leone M, Bugatti V, Saviano M, Vittoria V, De Luca S (2015) A biocompatible process to prepare hyaluronan-based material able to selfassemble into stable nano-particles. RSC Adv 5:29573-29576. https://doi.org/10.1039/c5ra03107a 
[21] Yin T, Wang J, Yin L, Shen L, Zhou J, Huo M (2015) Redox-sensitive hyaluronic acid-paclitaxel conjugate micelles with high physical drug loading for efficient tumor therapy. Polym Chem 6:8047-8059. https://doi.org/10.1039 /c5py01355k

[22] Luo P, Liu L, Xu W, Fan L, Nie M (2018) Preparation and characterization of aminated hyaluronic acid/oxidized hydroxyethyl cellulose hydrogel. Carbohydr Polym 199:170-177. https://doi.org/10.1016/j.carbpol.2018.06.065

[23] Zhang H, Hussain I, Brust M, Butler MF, Rannard SP, Cooper A (2005) Aligned two-and three-dimensional structures by directional freezing of polymers and nanoparticles. Nat Mater 4:787. https://doi.org/10.1038/nmat1487

[24] Hou S, Xu Q, Tian W, Cui F, Cai Q, Ma J, Lee I (2005) The repair of brain lesion by implantation of hyaluronic acid hydrogels modified with laminin. J Neurosci Methods 148:60-70. https://doi.org/10.1016/j.jneumeth.2005.04.016

[25] Garcia-Rill E, D’Onofrio S, Luster B, Mahaffey S, Urbano FJ, Phillips C (2016) The $10 \mathrm{~Hz}$ frequency: a fulcrum for transitional brain states. Trans Brain Rhythm 1(1):7-13

[26] Saha K, Keung AJ, Irwin EF, Li Y, Little L, Schaffer DV (2008) Substrate modulus directs neural stem cell behavior. Biophys J 95:4426-4438. https://doi.org/10.1529/biophysj. 108.132217

[27] Nicodemus GD, Bryant S (2008) Cell encapsulation in biodegradable hydrogels for tissue engineering applications. Tissue Eng Part B rev 4:149-165. https://doi.org/10.1089/te n.teb.2007.0332

[28] Omidian H, Rocca JG, Park K (2005) Advances in superporous hydrogels. J Control Release 102:3-12. https://doi. org/10.1016/j.jconrel.2004.09.028

[29] Führmann T, Obermeyer J, Tator CH, Shoichet MS (2015) Click-crosslinked injectable hyaluronic acid hydrogel is safe and biocompatible in the intrathecal space for ultimate use in regenerative strategies of the injured spinal cord. Methods 84:60-90. https://doi.org/10.1016/j.ymeth.2015.03.023

[30] Nimmo CM, Owen SC, Shoichet MS (2011) Diels-Alder click cross-linked hyaluronic acid hydrogels for tissue engineering. Biomacromol 12:824-830. https://doi.org/10.1 021/bm101446k

[31] Zhuo F, Liu X, Gao Q, Wang Y, Hu K, Cai Q (2017) injectable hyaluronan-methylcellulose composite hydrogel crosslinked by polyethylene glycol for central nervous system tissue engineering. Mater Sci Eng C 81:1-7. https://doi. org/10.1016/j.msec.2017.07.029
[32] Xiao W, He J, Nichol JW, Wang L, Hutson CB, Wang B, Du Y, Fan H, Khademhosseini A (2011) Synthesis and characterization of photocrosslinkable gelatin and silk fibroin interpenetrating polymer network hydrogels. Acta Biomater 6:2384-2393. https://doi.org/10.1016/j.actbio.2011.01.016

[33] Xiao W, Li J, Qu X, Wang L, Tan Y, Li K, Li H, Yue X, Li B, Liao X (2019) Cell-laden interpenetrating network hydrogels formed from methacrylated gelatin and silk fibroin via a combination of sonication and photocrosslinking approaches. Mater Sci Eng C 99:57-67. https://doi.org/10.1016/j. msec.2019.01.079

[34] Fares MM, Shirazi Sani E, Portillo Lara R, Oliveria RB, Khademhosseini A, Annabi N (2018) Interpenetrating network gelatin methacrylate (GelMa) and pectin-g-PCL hydrogels with tunable properties for tissue engineering. Biomater Sci 6:2938-2950. https://doi.org/10.1039/c8b $\mathrm{m} 00474 \mathrm{a}$

[35] Hong A, Aguilar M, Del Borgo MP, Sobey c, Broughton B, Forsythe J, (2019) Self-assembling injectable peptide hydrogels for emerging treatment of ischemic stroke. J Mater Chem B 7:3927-3943. https://doi.org/10.1039/c9tb00257j

[36] Suri S, Schmidt CE (2009) Photopatterned collagen-hyaluronic acid interpenetrating polymer network hydrogels. Acta biomater 5:2385-2397. https://doi.org/10.1016/j.actbio. 2009.05.004

[37] Suri S, Schmidt CE (2010) Cell-laden hydrogel constructs of hyaluronic acid, collagen, and laminin for neural tissue engineering. Tissue Eng Part A 16:1703-1716. https://doi. org/10.1089/ten.tea.2009.0381

[38] Nguyen LH, Gao M, Lin J, Wu W, Wang J, Chew SY (2016) Three-dimensional aligned nanofibers-hydrogel scaffold for controlled non-viral drug/gene delivery to direct axon regeneration in spinal cord injury treatment. Sci Rep. http s://doi.org/10.1038/srep42212

[39] Wang L, Wu Y, Hu T, Ma PX, Guo B (2019) Aligned conductive core-shell biomimetic scaffolds based on nanofiber yarns/hydrogel for enhanced 3D neurite outgrowth alignment and elongation. Acta Biomater 96:175-187. http s://doi.org/10.1016/j.actbio.2019.06.035

Publisher's Note Springer Nature remains neutral with regard to jurisdictional claims in published maps and institutional affiliations. 